\title{
Article \\ Effects of Environmental Conditions on Nephron Number: Modeling Maternal Disease and Epigenetic Regulation in Renal Development
}

\author{
Lars Fuhrmann ${ }^{1}$ D, Saskia Lindner ${ }^{2}$, Alexander-Thomas Hauser ${ }^{3}$, Clemens Höse ${ }^{2}$, Oliver Kretz ${ }^{1}$, \\ Clemens D. Cohen ${ }^{4}$, Maja T. Lindenmeyer ${ }^{1}$, Wolfgang Sippl ${ }^{5} \mathbb{D}^{\mathbb{D}}$, Manfred Jung ${ }^{3,6}{ }^{\mathbb{D}}$, Tobias B. Huber ${ }^{1}$ \\ and Nicola Wanner $1, * \mathbb{D}$
}

check for updates

Citation: Fuhrmann, L.; Lindner, S.; Hauser, A.-T.; Höse, C.; Kretz, O. Cohen, C.D.; Lindenmeyer, M.T.; Sippl, W.; Jung, M.; Huber, T.B.; et al. Effects of Environmental Conditions on Nephron Number: Modeling Maternal Disease and Epigenetic Regulation in Renal Development. Int. J. Mol. Sci. 2021, 22, 4157. https://doi.org/10.3390/ ijms 22084157

Academic Editor: Giuseppina T. Russo

Received: 23 March 2021

Accepted: 15 April 2021

Published: 16 April 2021

Publisher's Note: MDPI stays neutral with regard to jurisdictional claims in published maps and institutional affiliations.

Copyright: (c) 2021 by the authors. Licensee MDPI, Basel, Switzerland This article is an open access article distributed under the terms and conditions of the Creative Commons Attribution (CC BY) license (https:// creativecommons.org/licenses/by/ $4.0 /)$
1 III Department of Medicine, University Medical Center Hamburg-Eppendorf, 20246 Hamburg, Germany; la.fuhrmann@uke.de (L.F.); o.kretz@uke.de (O.K.); m.lindenmeyer@uke.de (M.T.L.); t.huber@uke.de (T.B.H.)

2 Department of Medicine IV, Faculty of Medicine, University of Freiburg, 79106 Freiburg, Germany; saskia.lindner@googlemail.com (S.L.); clemens.hoese@uniklinik-freiburg.de (C.H.)

3 Institute of Pharmaceutical Sciences, University of Freiburg, 79104 Freiburg, Germany; alexander.hauser@pharmazie.uni-freiburg.de (A.-T.H.); manfred.jung@pharmazie.uni-freiburg.de (M.J.)

4 Nephrological Center, Medical Clinic and Policlinic IV, University of Munich, 80336 Munich, Germany; Clemens.Cohen@klinikum-muenchen.de

5 Institute of Pharmacy, Martin-Luther-University of Halle-Wittenberg, 06120 Halle (Saale), Germany; wolfgang.sippl@pharmazie.uni-halle.de

6 CIBSS-Centre for Integrative Biological Signalling Studies, University of Freiburg, 79104 Freiburg, Germany * Correspondence: n.wanner@uke.de; Tel.: +49-474-103-5337

\begin{abstract}
A growing body of evidence suggests that low nephron numbers at birth can increase the risk of chronic kidney disease or hypertension later in life. Environmental stressors, such as maternal malnutrition, medication and smoking, can influence renal size at birth. Using metanephric organ cultures to model single-variable environmental conditions, models of maternal disease were evaluated for patterns of developmental impairment. While hyperthermia had limited effects on renal development, fetal iron deficiency was associated with severe impairment of renal growth and nephrogenesis with an all-proximal phenotype. Culturing kidney explants under high glucose conditions led to cellular and transcriptomic changes resembling human diabetic nephropathy. Shortterm high glucose culture conditions were sufficient for long-term alterations in DNA methylationassociated epigenetic memory. Finally, the role of epigenetic modifiers in renal development was tested using a small compound library. Among the selected epigenetic inhibitors, various compounds elicited an effect on renal growth, such as HDAC (entinostat, TH39), histone demethylase (deferasirox, deferoxamine) and histone methyltransferase (cyproheptadine) inhibitors. Thus, metanephric organ cultures provide a valuable system for studying metabolic conditions and a tool for screening for epigenetic modifiers in renal development.
\end{abstract}

Keywords: renal development; nephron number; diabetic nephropathy; epigenetic regulation; iron deficiency; DNA methylation

\section{Introduction}

Fetal development is affected by the in utero environment, and an adverse milieu can predispose to diseases such as hypertension, cardiovascular disease and chronic kidney disease later in life [1-4]. A range of intrauterine disturbances can result in a reduction in nephron endowment and compromised renal function in the offspring. In rodents, conditions leading to reduced nephron numbers at birth include intrauterine growth restriction (IUGR), maternal low protein diet, medications (including corticosteroids or nonsteroidal anti-inflammatory drugs), monogenetic mutations and low vitamin A levels, as well as maternal diabetes and iron deficiency [5-10]. In humans, there is currently no 
noninvasive method of measuring nephron numbers. However, postmortal studies have demonstrated a negative correlation between nephron numbers and blood pressure $[4,11]$. Additionally, intrauterine conditions associated with reduced nephron numbers such as IUGR are known to be are associated with increased rates of hypertension and CKD [12].

In vivo experiments where the adverse intrauterine conditions are artificially induced in pregnant animals have proven invaluable for the detection and description of the renal alterations induced in the offspring. However, any experimental intervention during gestation results in complex alterations in the maternal, placental and fetal physiology which may themselves affect the environment of the developing metanephroi. Ex vivo modeling techniques circumvent this by enabling the investigation of kidney development completely separated from the influence of the mother animal, the placenta or other organs of the fetus. Isolated cultures of metanephroi on a medium-air interface were initially performed by Trowell in 1950 [13] and have subsequently been refined by culturing of kidneys on filter membranes [14], providing a basis for single-variable culture conditions.

In summary, there is an increasing body of evidence suggesting that prenatal insults associated with low nephron numbers are relevant risk factors for hypertension and CKD. In order to develop preventative strategies to ensure adequate nephron endowment at birth, a mechanistic understanding of the factors influencing renal development and nephrogenesis is necessary. In the present work, metanephric organ culture was used to model different aspects of environmental regulation to study their effects on renal growth and possible implications for long-term renal function and used to screen for epigenetic regulators using FDA-approved small compounds.

\section{Results}

\subsection{Use of Metanephric Organ Cultures to Study the Effect of Environmental Conditions on} Renal Development

To model adverse environmental conditions, kidneys from embryonic day (E) 12.5 embryos were cultured at the medium-air interface (Figure 1A). To facilitate monitoring of nephron and glomerular development, Six2.Cre and Pod.Cre dual-fluorescent reporter mice were used, respectively (Figure 1B,C). A common condition during pregnancy is fever, which affects more than $10 \%$ of pregnancies during the first 16 weeks of gestation [15]. Heat is a well-characterized teratogen, and hyperthermia during pregnancy has been shown to lead to fetal abortion, growth retardation and developmental defects, such as renal agenesis, hypoplasia and low birth weight in several species [16-21]. To assess the impact of prolonged, fever-range hyperthermic conditions on kidney growth and nephron formation, kidneys were isolated and maintained at either 37 or $40^{\circ} \mathrm{C}$ (Figure 1D). After 7 days of culture, kidneys cultured at $40{ }^{\circ} \mathrm{C}$ were, on average, $18.36 \%$ smaller than their counterparts cultured under physiological conditions (Figure 1E). However, no significant difference in the number of glomeruli per kidney was found between the groups (Figure 1F). Nevertheless, the decreased overall growth of the kidneys demonstrates a negative effect of increased temperature on metanephric growth.

With an estimated 19\% of pregnant women suffering from iron-deficiency anemia [22], iron deficiency is one of the most widespread conditions with the potential to disturb renal development [23]. In vivo data have shown that renal growth, glomerular numbers and renal iron uptake are reduced during pregnancies affected by maternal iron deficiency [24]. In order to assess the impact of reduced transferrin-bound iron supply on kidney growth and nephrogenesis, explants were cultured in medium containing $50 \mu \mathrm{g} / \mathrm{mL}$ of ironsaturated holo-transferrin or $50 \mu \mathrm{g} / \mathrm{mL}$ of iron-depleted apo-transferrin, respectively. Iron-restricted kidneys remained much smaller than their iron-sufficient counterparts and showed increased apoptosis in the ureteric buds and reduced ureteric bud branching and proliferation (Figure 1G, Supplementary Figure S1A-F). While the nephron population was morphologically unaffected, a decrease in the developing distal part of the nephron, as well as distal tubules, could be seen (Figure 1H,I, Supplementary Figure S1G-J). The iron-deficient kidneys were, on average, $47.9 \%$ of the size of their holo-transferrin cultured counterparts (Figure 1J) and showed a reduction in the overall number of glomeruli per 
kidney of $69.9 \%$ after 7 days in culture (Figure 1K). Thus, iron depletion by apo-transferrin showed severe effects on kidney growth with an all-proximal nephrogenesis phenotype.

A
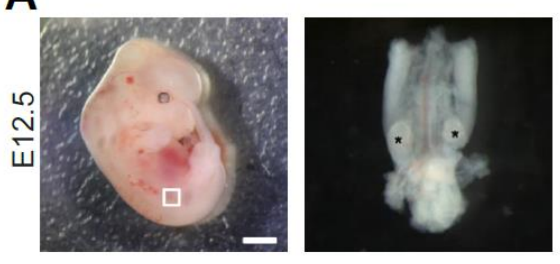

D

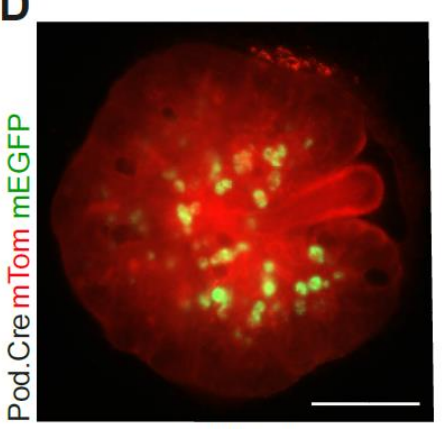

$37^{\circ} \mathrm{C} \quad$ Incubation temperature
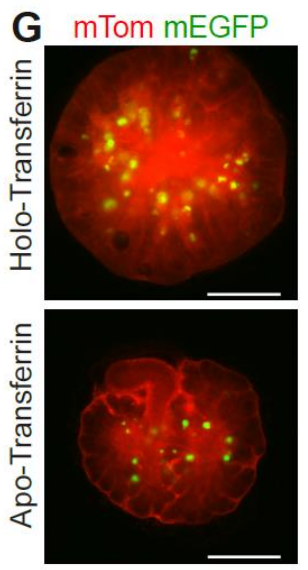
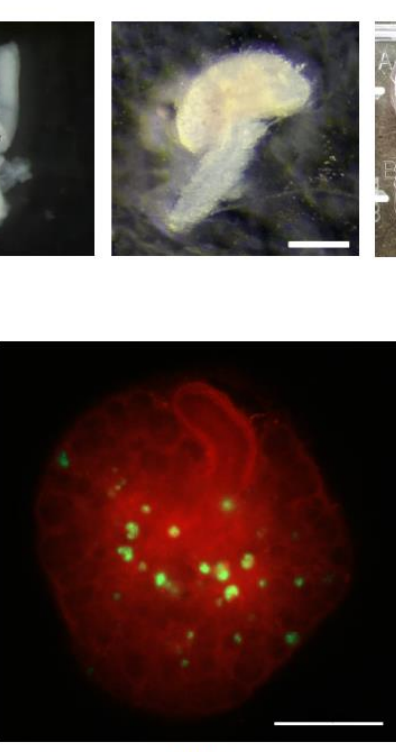

$40{ }^{\circ} \mathrm{C}$
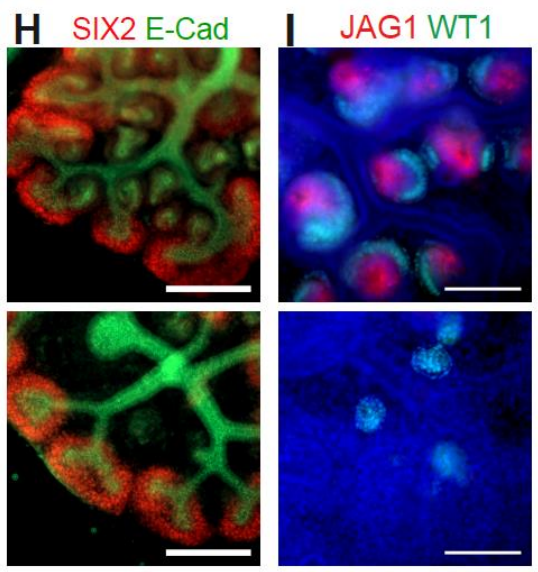
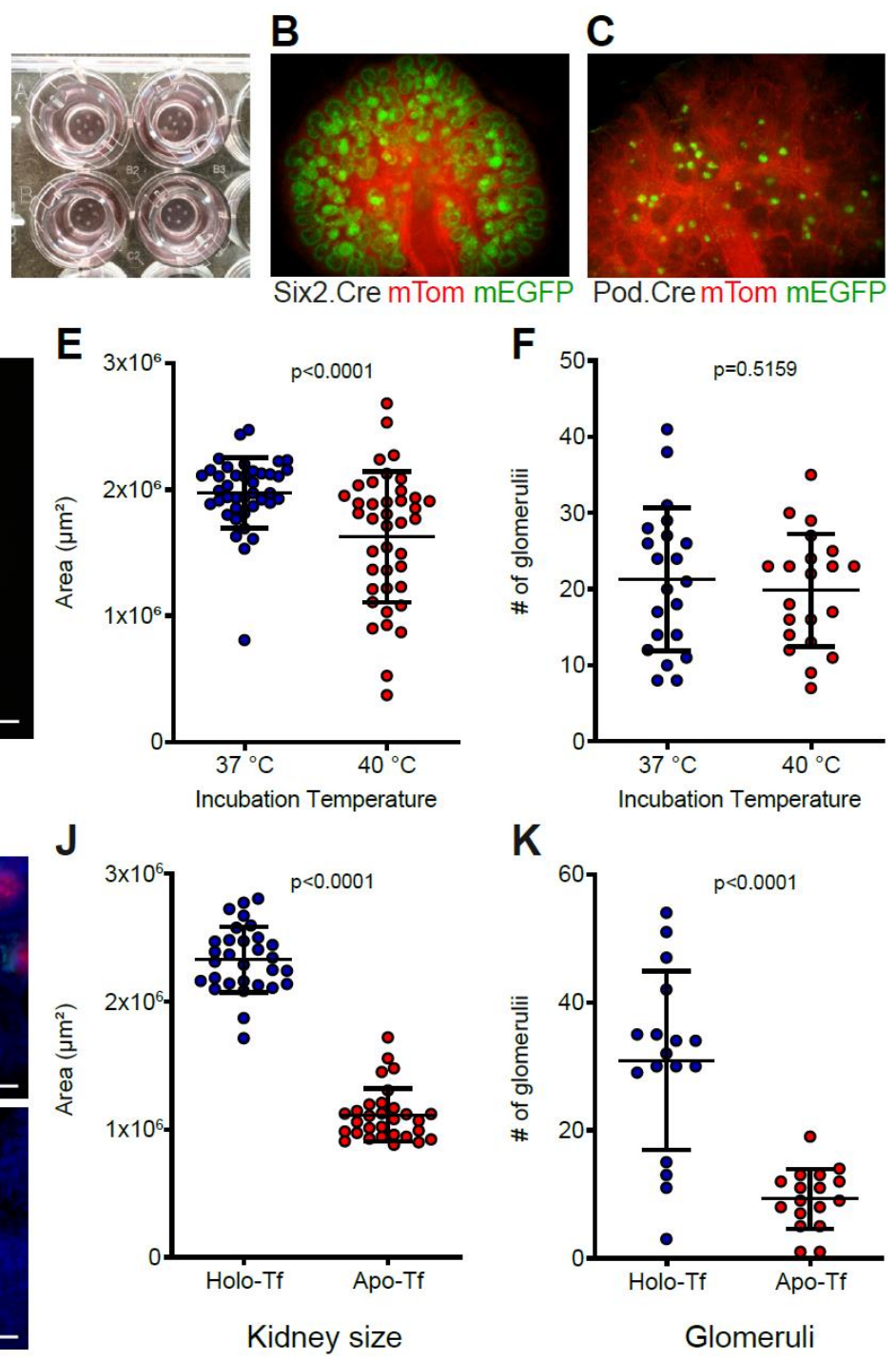

Figure 1. Use of metanephric organ cultures to study the effect of environmental conditions on renal development. (A) The urogenital ridge from E12.5 mouse embryos (left panel) was microsurgically extracted (second panel), and the kidneys were isolated (third panel) and placed on Transwell inserts (right panel). Scale bars: $1 \mathrm{~mm}$ (left panel), $500 \mu \mathrm{m}$ (third panel). (B) Transgenic mice with dual Tomato/EGFP expression were used for conditional labeling of Six2-positive cells and their offspring using Six2.Cre or (C) podocin-positive cells using Pod.Cre mice. (D) Explants from the same embryo cultured for 7 days at 37 or $40^{\circ} \mathrm{C}$. Scale bars: $500 \mu \mathrm{m}$. (E) Surface areas of explants grown for 7 days at 37 or $40{ }^{\circ} \mathrm{C}$. $\mathrm{n}=40$ pairs, paired $t$-test, mean \pm SD. (F) Number of glomeruli in the explant groups after 7 days. $\mathrm{n}=21$ pairs, paired $t$-test, mean \pm SD. (G) Explants from the same embryo cultured for 7 days in medium containing holo-Tf or apo-Tf. Scale bars: $500 \mu \mathrm{m}$. (H) Widefield images of holo-Tf and apo-Tf cultured explant pair stained against SIX2 and E-cadherin after $48 \mathrm{~h}$ of culture show normal progenitor cell pool and defects in early nephron morphology. Scale bar: $100 \mu \mathrm{m}$. (I) Widefield images of holo-Tf and apo-Tf cultured explant pair stained against WT1 and JAG1. Scale bars: $100 \mu \mathrm{m}$. (J) Surface areas of holo-Tf and apo-Tf cultured explants after 7 days. $\mathrm{n}=30$ pairs, paired $t$-test, mean $\pm \mathrm{SD}$. (K) Number of glomeruli in the explant groups after 7 days. $\mathrm{n}=17$ pairs, paired $t$-test, mean \pm SD. 


\subsection{Ex Vivo High Glucose Exposure Leads to Diabetic Nephropathy-Associated Changes in the Developing Kidney}

Maternal diabetes is another common condition during pregnancy, with a global prevalence of hyperglycemia in pregnancy of $\sim 17 \%$ and over 20 million live births each year [25]. Diabetes induced in mouse and rat models has been shown to lead to offspring with a lower nephron number $[10,26,27]$. Metanephric organ culture has been used before to study the effect of high glucose on renal development [27-29]. Previously, we reported reduction in size, nephron number and DNA methylation under high glucose conditions of $55 \mathrm{mM}$ [30]. In contrast to published data [28], no effect on explant size or glomerular number could be seen in our samples when cultured in different $30 \mathrm{mM}$ glucose media compared to $5 \mathrm{mM}$ control conditions after 7 days (Supplementary Figure S2A,B). Furthermore, no decrease in DNA methylation at LINE-1 and major satellite sites could be detected (Supplementary Figure S2C,D). The effect of $55 \mathrm{mM}$ high glucose on renal development after a 7-day period culture was further analyzed, showing a decrease in the growth rate starting at day 3 in culture (Figure 2A,B). Immunofluorescence stainings showed no morphological defects of the SIX2-positive progenitor cell pool (Figure 2C) but showed reduced staining of podocyte marker podocalyxin (PODXL, Figure 2D). The glomeruli were found to contain a thickened glomerular basement matrix visible in histological stainings (Figure 2E). Similar findings were made in electron microscopy, showing an increase in glomerular basement membrane thickness (Figure 2F), one of the earliest markers of prediabetes and diabetic nephropathy (DN) [31,32], in five out of six kidneys and none of seven littermate control kidneys. To further unravel changes in the transcriptome, pairwise differential gene expression (DGE) analysis of kidney cultures from three litters was performed, with one kidney from each embryo cultured with high glucose and the other with control medium and the kidneys pooled for analysis $(n=3)$. DGE confirmed the upregulation of extracellular matrix components as the primary upregulated biological process (Supplementary Table S1). Downregulated genes were mainly involved in (immune) cell activation and exocytosis/secretion (Supplementary Table S1). Mammalian phenotype ontology indicated abnormal kidney cortex and renal corpuscle morphology due to downregulated genes such as Pdgfb, Podxl, Ren, Ptpro, Mafb and Vegfa (Supplementary Table S1). Renal expression of several genes, such as Angptl4, Spon2 (Mindin), Pappa and Txnip, which have been shown to be upregulated in diabetic nephropathy [33-36], was found to be increased under hyperglycemic conditions. To compare the high glucose kidney culture gene expression profile to human DN, the DGE data were matched to human data from microdissected glomeruli and tubules from diabetic nephropathy patient biopsies from the European Renal cDNA Bank (ERCB). From the 216 differentially regulated genes matched after batch analysis, 94 genes were correspondingly differentially regulated in the glomerular and/or tubular fractions (Figure 2G). The overlap of our model and human DN genes showed 40 out of 95 genes upregulated in the glomeruli and 34 genes in tubules (25 genes in common) (Figure $2 \mathrm{H}$ ). The genes were mostly involved in extracellular matrix organization (COL4A5, COL4A6, COL8A2, LAMB3, LAMC3) and cell adhesion (ITGBL1, CLDN15). Additionally, diabetes-associated genes such as TXNIP, SPON2 and PAPPA were upregulated. Out of 120 downregulated genes from the kidney cultures, 22 were also downregulated in the glomeruli and 39 were also downregulated in the tubules (16 in common (Figure 2I). These genes were involved in response to endogenous stimulus (BMP2, KLF15, JUNB, CTSB), nephron epithelium development (PTPRO, PODXL, VEGFA) and positive regulation of endothelial cell chemotaxis (LGMN, P2RX4, VEGFA). Additionally, diabetes-associated genes such as RASGRP3, SIRPA, GATM and ESM1 were downregulated [37-39]. Differentially regulated genes not overlapping with ERCB data also reflected diabetes-associated changes, such as extracellular matrix (ANGPTL4, TNN, DPT, COL9A2) or gestational diabetes (LAT2, HP, CXCL10, CD86, CD68, REN, SLC2A3, VCAM1). Thus, renal development under high glucose conditions displayed remarkable similarities to human adult diabetic nephropathy. 
A
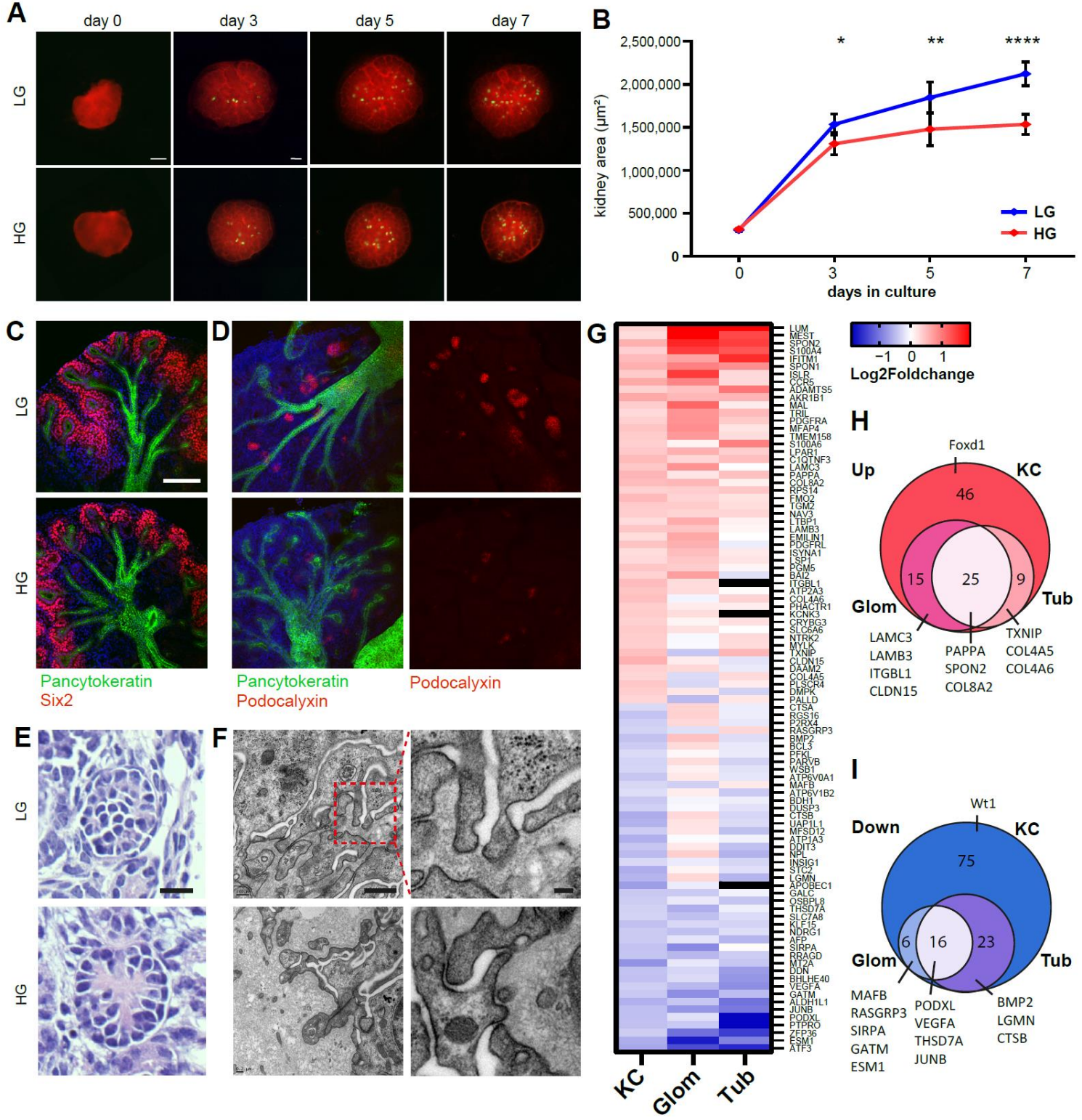
Pancytokeratin

$$
\begin{aligned}
& \text { ITGBL1 } \\
& \text { CLDN15 }
\end{aligned}
$$

\section{I}

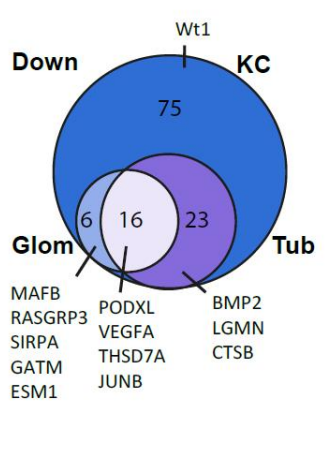

Figure 2. Ex vivo high glucose exposure leads to diabetic nephropathy-associated changes in the developing kidney. (A) Embryonic kidneys from Pod.Cre;Tomato/EGFP animals cultured for 7 days in low glucose (LG, $5.5 \mathrm{mM} \alpha$-D-glucose, $55 \mathrm{mM}$ mannitol) or high glucose (HG, $55 \mathrm{mM} \alpha$-D-glucose) conditions. Scale bar: $500 \mu \mathrm{m}$. (B) Kidney surface area of HG and LG conditions. ${ }^{*}, p=0.0474 ;{ }^{* *}, p=0.0052 ;{ }^{* * *}, p<0.0001$. Paired $t$-test, mean \pm SD. (C) Confocal immunofluorescent stainings of day 7 kidney cultures against Six2 and (D) podocalyxin with pan-cytokeratin and Hoechst. Scale bar: $100 \mu \mathrm{m}$. (E) Stainings of $6 \mu \mathrm{m}$ sections from day 7 kidney cultures. Scale bar: $20 \mu \mathrm{m}$. (F) Transmission electron microscopy of sections from day 7 kidney cultures. Glomerular basement membranes are thickened in kidneys exposed to high glucose conditions. Left column: magnification showing podocyte foot processes. Scale bars: $500 \mathrm{~nm}$ (left panels), $100 \mathrm{~nm}$ (right panels). (G) Fold change of RNA-seq data from HG compared to LG kidneys and ERCB diabetic nephropathy (DN) patient microarray data from microdissected glomeruli and tubules showing differentially expressed genes. $(\mathbf{H}) \mathrm{Genes}$ upregulated in the kidney cultures (KC) overlapping with ERCB DN patient data and selected genes highlighted. (I) Genes downregulated in the kidney cultures $(\mathrm{KC})$ overlapping with ERCB DN patient data and selected genes highlighted.

\subsection{Ex Vivo High Glucose Exposure Influences to Long-Term Memory Formation via DNA Methylation}

To further understand the molecular changes mediated by a hyperglycemic environment, kidney cultures were grown at high glucose conditions for 3.5 days and then changed to low glucose conditions for the same amount of time (Figure 3A). Remarkably, incuba- 
tion under physiological conditions after the shorter incubation period in high glucose medium did not reverse growth reduction after 7 days in culture with the cultures growing at the same rate as under continuous high glucose treatment (Figure 3B). Furthermore, DNA methylation showed hypomethylation of LINE-1 element and major satellite loci (Figure 2C,D), as well as sustained DNA hypermethylation of the Ppargcla promoter, under both high glucose and reversed conditions (Figure 3E), indicating the formation of metabolic memory via DNA methylation due to the earlier adverse environmental conditions as a means of fetal programming.
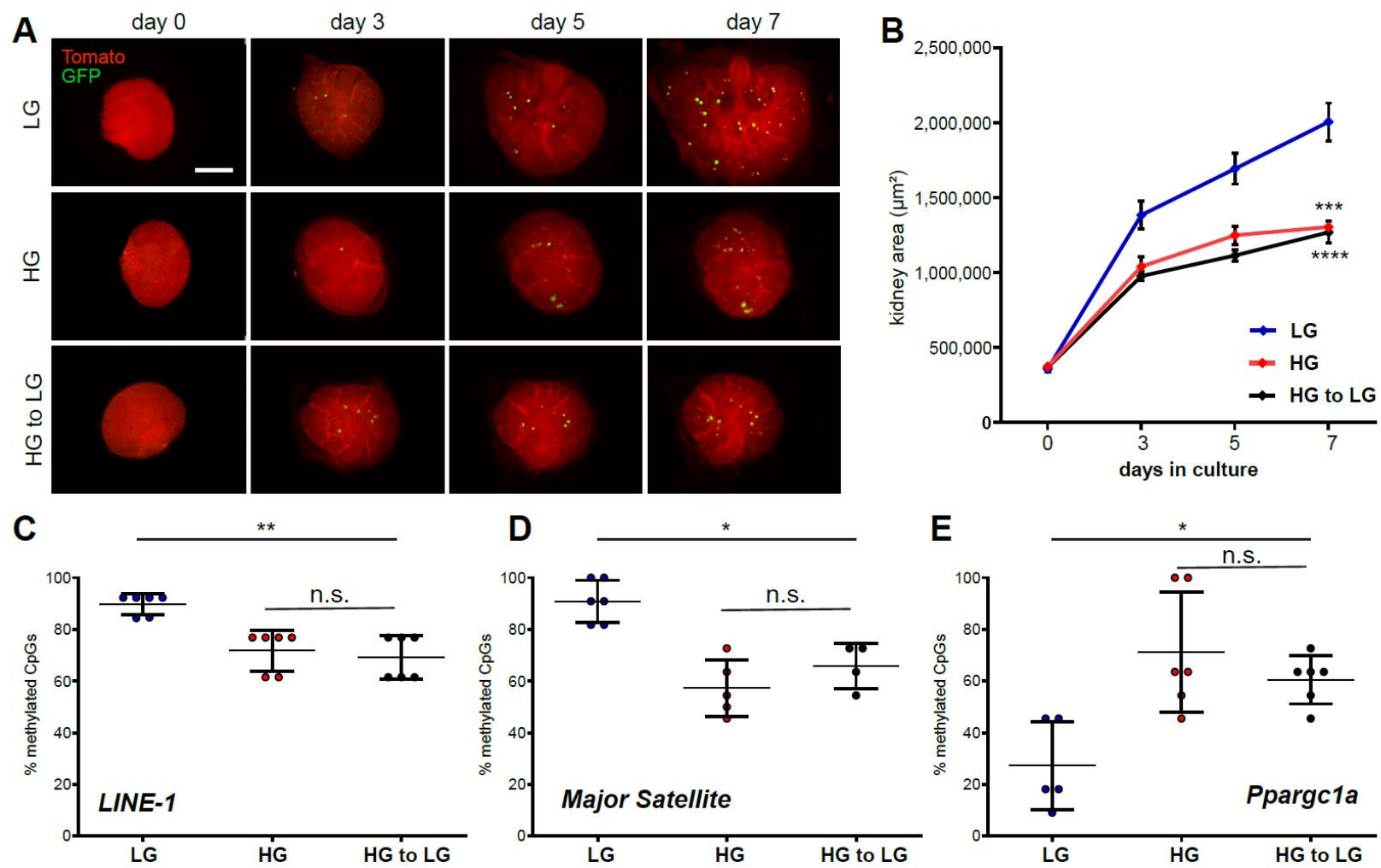

Figure 3. Ex vivo high glucose exposure influences long-term memory formation via DNA methylation. (A) Imaging of E12.5 embryonic kidneys from day 0 to day 7 in low glucose medium (5.5 mM), high glucose medium (55 mM) or high glucose medium for 3.5 days and reversal to low glucose medium for the remaining days. Scale bar: $500 \mu \mathrm{m}$. (B) Kidney surface area over 7 days. Mean \pm SD. $n=36$ kidneys. LG, low glucose treatment; HG, high glucose treatment; HG to LG, 3.5 days high and 3.5 days low glucose treatment. ${ }^{* * *}$, LG-HG (unpaired $t$-test): $p=0.0004 ;{ }^{* * * *}$, LG-HG to LG (paired $t$-test): $p<0.0001$. (C) Analysis of the DNA methylation at LINE-1 and (D) major satellite loci shows continuous DNA hypomethylation in high glucose treated conditions. ${ }^{* *}, p$-value $=0.0022 .{ }^{*}, p$-value $=0.0357$. (E) Analysis of the DNA methylation at Ppargc1a locus shows continuous DNA hypermethylation in high glucose conditions. Mean \pm SD. $*, p$-value $=0.0130$.

\subsection{Ex Vivo Small Compound Screen Identifies Epigenetic Regulators of Renal Development}

The results of this work as well as previous works suggest that epigenetic mechanisms play a role in kidney development [30,40-45]. Therefore, we wanted to systematically evaluate the effect of epigenetic modulators of the different enzyme classes on renal development. For this, we selected a library of $22 \mathrm{FDA}$-approved small compounds with demonstrated inhibitory activity [46-56] (Figure 4A). Using Six2.Cre-reporter mice to evaluate nephron development, the renal structures were cultured for 3 days with the inhibitors in the medium. Size increase over time was compared to the littermate control organs, and the morphology was checked for abnormalities in development (Figure 4B). Several inhibitors could be shown to interfere with normal ex vivo renal development. HDAC inhibitor entinostat, a benzamide histone deacetylase inhibitor with high affinity for HDAC 
1,2 and 3 [57], showed consistent growth reduction and lack of differentiation and proliferation after 3 days (Figure 4C). TH39, developed as a selective HDAC8 inhibitor (IC 50 HDAC8 88 nM, 26-fold selective against HDAC1, 28-fold selective against HDAC6 [56]), showed a similarly severe inhibition of growth compared to littermate control organs. Furthermore, iron chelators and inhibitors of JmJC deferasirox and deferoxamine showed growth reduction analogous to iron-deficient medium. Additionally, SET7/9 inhibitor cyproheptadine $[58,59]$ showed growth reduction and lack of differentiation and proliferation compared to control kidneys (Figure 4D) but also seemed to interfere with Wnt signaling (Supplementary Figure S3). Other HDAC, HAT, HDM and HMT inhibitors and DNMT inhibitor 5-azacytidine did not show growth reduction or developmental anomalies within the measured time frame (Figure $4 \mathrm{~A}$ ).

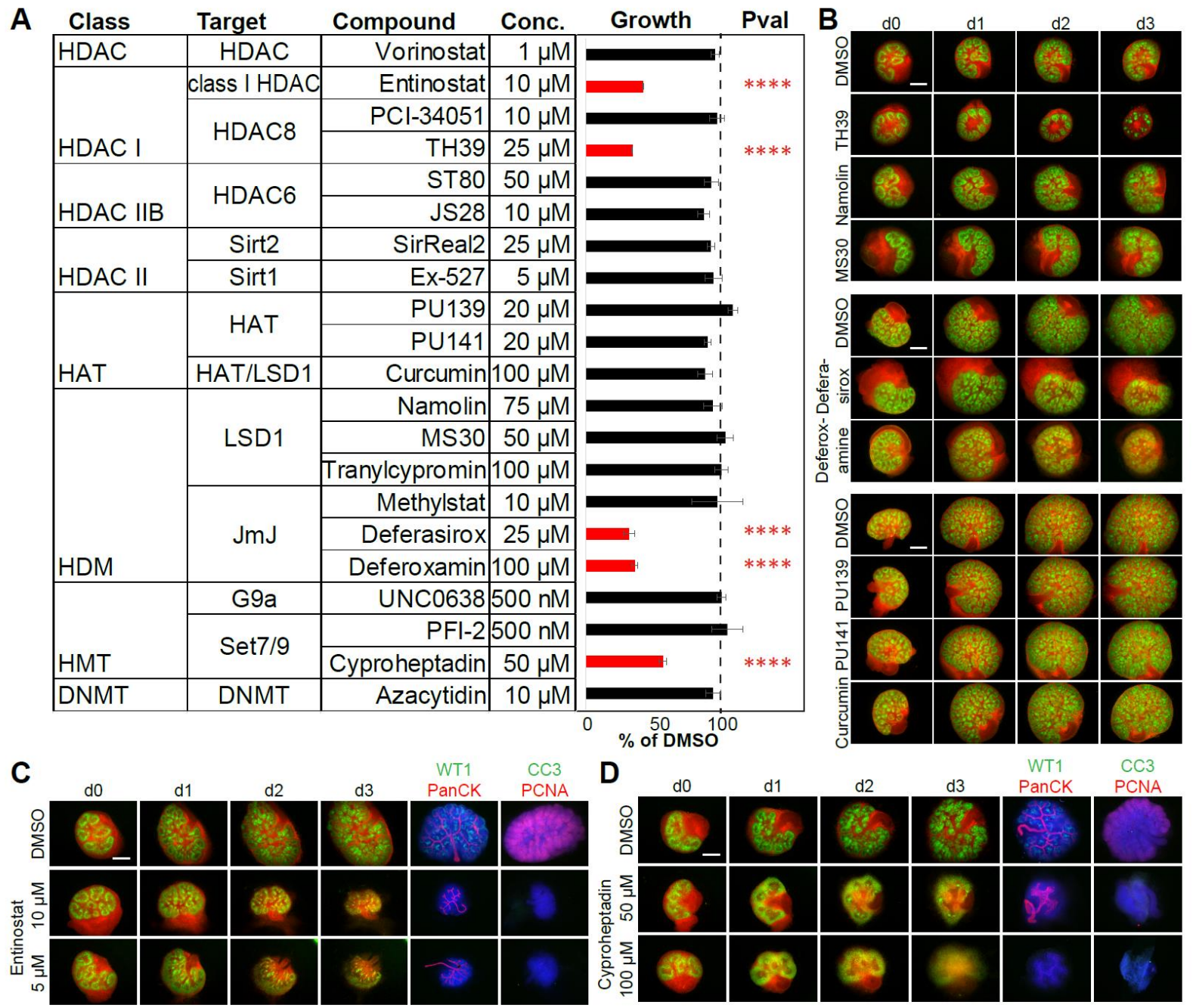

Figure 4. Ex vivo small compound screen identifies modulators of renal development. (A) List of small compounds, their epigenetic targets and concentration used shows renal growth reduction with entinostat, TH39, deferasirox, deferoxamine and cyproheptadine in $\geq 3$ independent experiments after 3 days in culture. Control cultures were treated with DMSO. $* * * *, p$-value $<0.0001$. (B) Examples of two sets of embryonic kidney cultures with pictures taken from day 0 until day 3 showing growth reduction and morphological differences in kidneys treated with TH39, deferasirox and deferoxamine compared to littermate control kidneys. Scale bar: $500 \mu \mathrm{m}$. (C) Entinostat showed growth reduction at 5 and $10 \mu \mathrm{M}$ concentration, no nephron differentiation and lack of proliferation after 3 days. (D) Cyproheptadine showed growth reduction at 100 and $50 \mu \mathrm{M}$ concentrations, lack of differentiation, ureter dilation and lack of proliferation after 3 days in culture. Scale bar: $500 \mu \mathrm{m}$. PanCK, pan-cytokeratin. CC3, cleaved caspase-3. PCNA, proliferating cell nuclear antigen. 


\section{Discussion}

Renal development primarily takes place in utero and is subject to interference from metabolic and environmental influences. Nephron number is determined at birth, and a growing body of evidence suggests low nephron numbers to be a risk factor for the development of hypertension and chronic kidney disease later in life [2-4,60]. However, many factors influencing nephron number and modes of action are still unknown. Here, embryonic kidneys from dual-fluorescent reporter mice cultured on Transwell inserts were used to model maternal metabolic conditions and screen epigenetic inhibitors.

While many studies now involve kidney organoids using human iPS cells [61], kidney cultures are a valuable tool for detailed analysis of phenotypes mediated by metabolic conditions or inhibitory agents. While progenitor cell cultures and kidney organoids are alternatives with significant potential for investigations of teratogenicity, they are subject to limitations, such as high variability in differentiation and growth and lack of a conventional organ structure. This makes metanephric organ culture a valuable alternative to investigate conditions that would not be feasible in vivo.

Thus, hyperthermia and iron deficiency provide two examples of investigating environmental conditions with different outcomes on renal growth and nephron numbers. While data on the effect of hyperthermia on renal growth are scarce, the effect of ex vivo iron restriction is in line with previous reports of maternal iron deficiency in rats [23,24], although the model is limited in replicating the exact in utero state in terms of concentration and iron kinetics. Our results have also shown that mitotic activity is reduced in the iron-restricted condition. Iron plays an essential role in many cellular processes, such as the cell cycle [62]. Our morphological analysis showed an all-proximal nephron differentiation phenotype, possibly as the result of inhibited canonical Wnt signaling. Widespread downregulation of genes associated with Wnt signaling has previously been reported in a microarray analysis of rat offspring exposed to maternal iron deficiency [63]. Mechanistically, intracellular iron depletion by chelating agents has been shown to induce proteasomal degradation of $\beta$-catenin, the principal downstream effector protein of the canonical Wnt pathway in cancer and neural progenitor cells [64,65].

As another metabolic condition, modeling high glucose exposure resulted in effects similar to those of in vivo streptozotocin-induced maternal diabetes $[10,26,27,66-71]$. While our model could not reproduce the effects of $30 \mathrm{mM}$ glucose conditions, likely due to the previously reported influence of mouse background [28,72], $55 \mathrm{mM}$ glucose conditions resulted in growth reduction and decreased nephron numbers. Pronounced changes were visible histologically and ultrastructurally in the glomeruli, with the expansion of the glomerular basement matrix resembling human diabetic nephropathy. The similarities between murine fetal and human adult renal response to high glucose with distinct ECM expansion and downregulation of key podocyte genes was striking and revealed many known diabetes-associated genes, indicating usage of similar mechanisms in the podocytes and tubules. However, whether the same underlying pathways lead to dedifferentiation in diabetic nephropathy and decrease in differentiation during fetal differentiation is so far unknown. Interestingly, nonglucose alterations of the diabetic environment, such as hyperketonemia, have also been shown to mediate teratogenesis but were not replicated in the kidney culture model $[73,74]$. Long-term effects of hyperglycemia were also reproducible in our model, showing continuous growth retardation after normalization of glycemia similar to previous reports [10]. Additionally, DNA methylation analysis revealed a prolonged DNA hypomethylation at repetitive regions and hypermethylation at the Ppargc1a locus after reversal to low glucose medium, indicating the formation of metabolic memory after a period of metabolic stress [30]. Many more of the differentially regulated genes have also previously been shown to be epigenetically regulated in diabetes. For instance, upregulated gene MEST is maternally imprinted and hypomethylated in gestational diabetes mellitus [75]. S100A4 is a differentially methylated marker of insulin resistance in obese children [76]. Of the downregulated genes, ESM1 and RASGRP3 are examples of genes differentially methylated in gestational diabetes $[77,78]$, showing the growing emergence 
of links between diabetes and epigenetic regulation. Thus, our system highlights epigenetic modification or fetal programming as an important regulatory mechanism.

Several epigenetic regulatory enzymes are known to be involved in both renal morphogenesis and transcriptional regulation in adult organ function and disease [30,40,79-81] Using kidney cultures as a screening tool, we searched for additional epigenetic modifiers playing a role in renal development and nephron morphogenesis. Entinostat (MS-275) reduced kidney size concordant with previously reported genetic deletion of HDAC1 and HDAC2 in either nephron progenitor cells or ureteric bud cells $[44,82,83]$. While inhibition of HDAC 8 by TH39 also induced a severe growth reduction of the explant and lack of differentiation, the highly specific HDAC8 inhibitor PCI-34051 showed no effect, thus pointing to off-target effects of TH39, such as other HDACs. With a phenotype similar to that of kidneys cultured under iron-deficient conditions, deferasirox and deferoxamine, published inhibitors of the iron-dependent JumonjiC-domain-containing histone demethylases [50], may exhibit off-target effects due to iron chelation. While cyproheptadine, a histamine antagonist and published inhibitor of Set7/9 histone methyltransferase, displayed a unique phenotype by leading to diffusion of the progenitor cell population, additional results pointed to off-target effects involving the Wnt signaling pathway [48]. Altogether, this library of FDA-approved inhibitors shows the potential for fast and effective screening for epigenetic modulators. Due to the limited time frame used, inhibitors requiring prolonged exposure to exert an effect might have been missed in this setup. Thus, azacytidine did not show an effect despite the published phenotype of Dnmt1 knockout [30].

While the kidney culture system offers robust renal development, several aspects limit investigation or interpretation of the results in this reductionist model. First, studies have shown differences in mouse and human development and gene expression, limiting the use of the mouse model. Next, time limitations in this system may not allow for all complex processes to unfold. This may account for some of the environmental conditions and epigenetic inhibitors failing to impact renal development in this study. Moreover, some of the inhibitors show nonspecific effects that can contribute to inhibition of other pathways, such as in the case of cyproheptadine, which appears to exhibit its effect via activation of GSK3-beta, or the case of iron chelation by deferasirox/deferoxamine. Beyond this proof-of-concept study, the epigenetic inhibitor screen could be extended to more (specific) inhibitors; prolonged time periods; additional study criteria, such as nephron number and ureteric bud branching; and transcriptomic and epigenetic studies.

To summarize, kidney cultures enable the characterization of a number of maternal disease models, such as hyperthermia, iron deficiency and maternal diabetes, and the screening of pharmacological compounds, providing a well-suited platform for investigating the crosstalk between environmental influences of the developing kidney and its epigenetic programming.

\section{Materials and Methods}

\subsection{Animal Handling}

Mice were kept in a specific-pathogen-free environment at the Center for Experimental Models and Transgenic Service (CEMT) in Freiburg, Germany. All mice were raised in a $12 / 12 \mathrm{~h}$ cycle of light and darkness, with access to water and standard chow ad libitum. All experiments were registered with the regional government of Baden-Wuerttemberg under the authorization codes X15/03R and X17/05F.

\subsection{Timed Harvest of Embryos/Microdissection/Culture of Metanephroi}

Timed-pregnant hNPHS2Cre B6.129(Cg)-Gt(ROSA)26Sortm4(ACTB-tdTomato,-EGFP) Luo/J [5] and Tg(Six2-EGFP/cre)1Amc/J mice [84] were sacrificed at E12.5, and the embryos were harvested. The metanephroi were isolated and cultured on Transwell inserts with culture medium at the medium-air interface. Pairing of metanephroi from the same embryo between control and experimental conditions was maintained throughout the experiments unless mentioned otherwise. 


\subsection{Genotyping}

Genotyping of the mice was performed by polymerase chain reaction (PCR) amplification of DNA isolated from tail biopsies and subsequent visualization of the amplified fragments by gel electrophoresis. The following primers were used: Tomato/EGFP forward 5' CTC TGC TGC CTC CTG GCT TCT $3^{\prime}$ reverse wildtype 5' CGA GGC GGA TCA CAA GCA ATA $3^{\prime}$ and reverse mutant $5^{\prime}$ TCA ATG GGC CGG GGT CGT T3', Cre forward $5^{\prime}$ GCA TTA CCG GTC GAT GCA ACG AGT GAT GAG $3^{\prime}$ and reverse $5^{\prime}$ GAG TGA ACG AAC CTG GTC GAA ATC AGT GCG 3'.

\subsection{Hyperglycemic Conditions}

Hyperglycemia medium contained DMEM medium with 10\% fetal bovine serum, $100 \mu \mathrm{g} / \mathrm{mL}$ of penicillin, $100 \mu \mathrm{g}$ of streptomycin and D-glucose for a final concentration of $55 \mathrm{mM}$ D-glucose. For the control medium, an equimolar amount of mannitol was added, for a final concentration of $5 \mathrm{mM}$ of D-glucose and $50 \mathrm{mM}$ mannitol.

\subsection{Hyperthermic Conditions}

For both hyperthermia and control cultures, a serum-free base medium of 1:1 DMEM and Ham's F-12 Medium was supplemented with $100 \mu \mathrm{g} / \mathrm{mL}$ of penicillin, $100 \mu \mathrm{g} / \mathrm{mL}$ of streptomycin, $50 \mu \mathrm{g} / \mathrm{mL}$ of bovine holo-transferrin and $10 \mathrm{mM}$ HEPES for increased buffering capacity. Control cultures were incubated at $37^{\circ} \mathrm{C}$, while hyperthermia cultures were incubated in an identical incubator at a temperature of $40^{\circ} \mathrm{C}$.

\subsection{Iron-Restriction}

Iron-restricted medium consisted of serum-free base medium of 1:1 DMEM and Ham's F-12 medium which was supplemented with $100 \mu \mathrm{g} / \mathrm{mL}$ of penicillin, $100 \mu \mathrm{g} / \mathrm{mL}$ of streptomycin and $50 \mu \mathrm{g} / \mathrm{mL}$ of apo-transferrin. For the iron-sufficient control cultures, $50 \mu \mathrm{g} / \mathrm{mL}$ of holo-transferrin was used instead.

\subsection{Whole Mount Immunofluorescence Staining of Explants}

Cultured explants were either fixed with cold methanol for $20 \mathrm{~min}$ or room-temperature $4 \%$ paraformaldehyde (PFA) solution for $15 \mathrm{~min}$ and subsequently washed three times with room temperature PBST buffer (PBS $+0.1 \%$ Tween 20) for $5 \mathrm{~min}$. Blocking solution containing 5\% BSA in PBST buffer was added for $3 \mathrm{~h}$ at room temperature. After blocking, the cultures were incubated in dilutions of the primary antibodies in blocking solution at $4{ }^{\circ} \mathrm{C}$ on an orbital shaker overnight. Cultures were then washed three times with blocking solution for $2 \mathrm{~h}$ each and incubated in a 1:300 dilution of secondary antibodies and 1:500 dilution of Hoechst nuclear dye in blocking solution overnight. The cultures were again washed three times for $2 \mathrm{~h}$ and mounted with Prolong Gold Antifade mountant using a spacer. The following primary antibodies were used: rabbit anti-active caspase 3 (1:250, AF835; R\&D systems Inc., Minneapolis, MN, USA), rabbit anti-JAG-1 (1:100, 260S; Cell Signaling Technology, Denver, MA, USA), sheep anti-Tamm-Horsefall protein (1:250, AB2606308; Thermo Fisher Scientific, Waltham, MA, USA), mouse anti-pan-cytokeratin (1:250, AB11213; Abcam, Cambridge, UK), rabbit anti-SIX2 (1:100, 11562-1-AP; Proteintech Group Inc., Manchester, UK), mouse anti-WT1 (1:100, 05-753; Merck KGaA, Darmstadt, Germany), rat anti-CD326 (1:100; 118202, Biolegend, San Diego, CA), rabbit anti-NKCC2 (1:100, SPC-401D; StressMarq Biosciences, Victoria, BC, Canada), mouse anti-phospho-histone H3 (1:100, 9706S, Cell Signaling Technology, Denver, MA, USA) and mouse anti-E-cadherin (1:200, 4A2C7; Thermo Fisher Scientific, Waltham, MA, USA). The following secondary antibodies were used in 1:300 dilution: Alexa Fluor 488 anti-mouse (R37114) and antirabbit (R37118); Alexa Fluor 555 anti-mouse (A-31570), anti-rabbit (A-31572), anti-sheep (A-21436) and anti-rat (A-21434) (all Thermo Fisher). The pairing of explants from the same embryo was not maintained in the stainings against phospho-histone $\mathrm{H} 3$ due to the explants detaching from the membrane during PFA fixation. 


\subsection{Imaging}

Live imaging of cultured metanephroi from NPHS2-Cre;Tomato/EGFP mice was performed with Zeiss AxioObserver after mounting the membrane inserts on a glassbottom dish containing $200 \mu \mathrm{L}$ of cold PBS. Live images were taken as z-stacks with a plane distance of $10 \mu \mathrm{m}$. For the glomerular counting, the z-stacked GFP channels were orthogonally projected using Zen Blue and analyzed with ImageJ. Stained cultures were imaged using Zeiss AxioObserver inverted microscope or U2 LSM 510 META laser scanning microscope. Mitotic cells were counted using ImageJ.

\subsection{Histology}

Fixation was performed in 4\% PFA solution overnight. The explants were dehydrated with ethanol, incubated with xylene and embedded in paraffin. The paraffin blocks were sectioned at $3 \mu \mathrm{m}$ and mounted onto glass specimen slides. Hematoxylin/eosin staining (H\&E) was performed.

\subsection{0. $E M$}

Kidney cultures were fixed in 4\% PFA/1\% glutardialdehyde in 1x PBS overnight and then embedded in liquid $40{ }^{\circ} \mathrm{C}$ agarose. After postfixation with $1 \%$ osmium tetroxide in $6.68 \%$ sucrose buffer, the samples were washed and stained en bloc with $1 \%$ uranyl acetate in $70 \%$ alcohol for $1 \mathrm{~h}$, dehydrated in ethanol and propylene oxide and embedded in Durcupan (Plano, Wetzlar, Germany). Ultrathin sections were stained with lead citrate and examined in a Zeiss-Leo 910 transmission electron microscope.

\subsection{Bisulfite-PCR}

DNA from kidney cultures was isolated with DNeasy Blood \& Tissue kit (QIAGEN) and bisulfite-converted using EpiTect Bisulfite Kit (QIAGEN) according to the manufacturer's instructions. Converted DNA (20 ng) was used as template in a PCR reaction using AmpliTaq Gold Polymerase (Invitrogen). PCR products were purified using gel electrophoresis and ligated into a pCR4-TOPO vector using the TOPO TA Cloning Kit for sequencing (Invitrogen) and transformed into DH10B E. Coli cells. Randomly selected clones were sent for sequencing (GATC, Konstanz). Inspection, alignment, visualization and statistics were performed with QUMA: quantification tool for methylation analysis [85]. The following primers were used: major satellite forward: 5' GGA ATA TGG TAA GAA AAT TGA AAA TTA TGG $3^{\prime}$, reverse: $5^{\prime}$ CCA TAT TCC AAA TCC TTC AAT ATA CAT TTC $3^{\prime}$, ref. [30] Line- 1 forward $5^{\prime}$ TAG GAA ATT AGT TTG AAT AGG TGA GAG GT 3', Line-1 reverse: TCA AAC ACT ATA TTA CTT TAA CAA TTC CCA $3^{\prime}$, ref. [30] Ppargcla forward 5' TGT TAG GGA ATA AGA TTT GTG TTT TTA A 3', Ppargcla reverse 5' CAA ATA CTC CTA TAA ACA ATC CAA ACA A $3^{\prime}$.

\subsection{RNA Sequencing}

The RNA of kidneys grown for 7 days under high or low glucose conditions was isolated using the Qiagen RNeasy Plus Mini Kit. RNA sequencing was performed by GATC Biotech. Quality control was done with FastQC (Barbraham Bioinformatics). Raw reads were trimmed using TrimGalore! (Barbraham Bioinformatics) and mapped with Tophat (v2) [86] to mm10 using Galaxy Freiburg. Read counts were extracted with htseq-count [87]; differential gene expression was analyzed with DESeq2 [88].

\subsection{Microarray Analysis of Human Kidney Biopsies}

Human kidney biopsy specimens and Affymetrix microarray expression data were procured within the framework of the European Renal cDNA Bank-Kröner-Fresenius Biopsy Bank. Biopsies were obtained from patients after informed consent and with the approval of the local ethics committees [89]. Following a renal biopsy, the tissue was transferred to RNase inhibitor and microdissected into glomeruli and tubulointerstitium. Total RNA was isolated from microdissected glomeruli and tubules, reverse transcribed and 
linearly amplified according to a protocol previously reported [90]. In this study, we used published microarray expression data from individual patients with diabetic nephropathy, as well as living donors (GSE 99340, LDs: GSE32591, GSE35489, GSE37463). CEL file normalization was performed with the Robust Multichip Average method using RMAExpress (Version 1.0.5) and the human Entrez-Gene custom CDF annotation from Brain Array Version 18, accessed on 23 January 2014 (http:/ /brainarray.mbni.med.umich.edu/ Brainarray/Database/CustomCDF/CDF_download.asp). The log-transformed dataset was corrected for batch effect using ComBat from the GenePattern pipeline (version 3.8.0) (http://www.broadinstitute.org/cancer/software/genepattern/). To identify differentially expressed genes, the SAM (Significance Analysis of Microarrays) method was applied using TiGR (MeV, Version 4.8.1) [91].

\subsection{4. $q P C R$}

mRNA was reverse transcribed to cDNA using the iScript cDNA synthase kit (BioRad) according to the manufacturer's instructions. qPCR was performed with BioRad CFX Connect Real-Time PCR Detection System in triplicates using SsoAdvanced Universal SYBR Green Supermix. The normalized $\triangle \triangle C T$ values were calculated in the CFX Manager program. The following primers were used: Jag1 forward 5' TGG TTG GCT GGG AAA TT $3^{\prime}$, Jag1 reverse $5^{\prime}$ TGG ACA CCA GGG CAC ATT C $3^{\prime}$, mHprt forward 5' GCT TTC CTT GGT CAA GCA GTA CAG 3', mHprt reverse 5' GAA GTG CTC ATT ATA GTC AAG GGC ATA TCC $3^{\prime}$ [92].

\subsection{Statistics}

For analysis of paired kidneys, paired $t$-tests were applied using GraphPad Prism 7. For the quantification of unpaired kidneys, pHH3-positive cells and qPCR experiments, unpaired $t$-test was applied.

Supplementary Materials: The following are available online at https:/ /www.mdpi.com/article/10 .3390/ijms22084157/s1, Figure S1: Ex vivo iron restriction as a model for metanephric development under iron-insufficient conditions, Figure S2: Ex vivo high glucose exposure does not influences long-term memory formation via DNA methylation at $30 \mathrm{mM}$ glucose concentration, Figure S3: Anti-histamine drug Cyproheptadine leads to progenitor cell loss via inhibition of Wnt signaling. Table S1: RNA-seq analysis of high glucose kidney cultures.

Author Contributions: Conceptualization, N.W., L.F. and T.B.H.; methodology, L.F., C.H., O.K., S.L. and N.W.; validation, L.F., S.L., C.H., O.K. and N.W.; formal analysis, L.F., S.L., C.H., O.K. and N.W.; resources, A.-T.H., M.J., W.S., M.T.L. and C.D.C.; data curation, N.W.; writing-original draft preparation, L.F. and N.W.; writing-review and editing, L.F., T.B.H., O.K., M.J., W.S. and N.W.; visualization, L.F., S.L., C.H., O.K. and N.W.; supervision, N.W. and T.B.H.; funding acquisition, T.B.H., O.K., M.J., M.T.L. and N.W. All authors have read and agreed to the published version of the manuscript.

Funding: This research was funded by the German Research Foundation (Deutsche Forschungsgemeinschaft, DFG): CRC 992 (to M.J. and T.B.H.), CRC 1192 (to T.B.H. and N.W.), Ju295/14-1 (to M.J.) Kr1984/4-1 (to O.K.) and under Germany's Excellence Strategy_EXC-2189-Project ID 390939984. Furthermore, this study was supported by the Heisenberg program (to T.B.H.), the European Research Council grant 616891 (to T.B.H.), the H2020-IMI2 consortium BEAt-DKD (Biomarker Enterprise to Attack Diabetic Kidney Disease) (115974, to T.B.H.), STOP-FSGS (Speed TranslationOriented Progress to Treat Focal Segmental Glomerulosclerosis) 01GM1901C (to T.B.H.), and the Else-Kröner Fresenius Stiftung (iPRIME (innovative Promotionsförderung im Bereich translationale Entzündungsforschung)). The Galaxy server that was used for some calculations is in part funded by Collaborative Research Centre 992 Medical Epigenetics (Deutsche Forschungsgesellschaft (DFG) grant SFB 992/1 2012) and the German Federal Ministry of Education and Research (Bundesministerium für Bildung und Forschung (BMBF) grants 031 A538A/A538C RBC, 031L0101B/031L0101C de.NBI-epi, 031L0106 de.STAIR(de.NBI)). 
Institutional Review Board Statement: The study was conducted according to the guidelines of the Declaration of Helsinki and approved by the Institutional Review Board (or Ethics Committee) of Klinikum der Universität München (250-16).

Informed Consent Statement: Informed consent was obtained from all subjects involved in the study.

Data Availability Statement: Raw and processed RNA-seq data will be made available on GEO upon publication.

Acknowledgments: ERCB-KFB was supported by the Else Kröner-Fresenius Foundation. We also thank all participating centers of the European Renal cDNA Bank-Kröner-Fresenius biopsy bank (ERCB-KFB) and their patients for their cooperation. For active members at the time of the study, see N. Shved et al., Scientific Reports 7, 8576 (2017).

Conflicts of Interest: The authors declare no conflict of interest.

\section{References}

1. Barker, D.J. The fetal and infant origins of adult disease. BMJ 1990, 301, 1111. [CrossRef]

2. Wang, X.; Garrett, M.R. Nephron number, hypertension, and CKD: Physiological and genetic insight from humans and animal models. Physiol. Genom. 2017, 49, 180-192. [CrossRef] [PubMed]

3. Hughson, M.D.; Douglas-Denton, R.; Bertram, J.F.; Hoy, W.E. Hypertension, glomerular number, and birth weight in African Americans and white subjects in the southeastern United States. Kidney Int. 2006, 69, 671-678. [CrossRef] [PubMed]

4. Keller, G.; Zimmer, G.; Mall, G.; Ritz, E.; Amann, K. Nephron number in patients with primary hypertension. N. Engl. J. Med. 2003, 348, 101-108. [CrossRef] [PubMed]

5. Lelievre-Pegorier, M.; Vilar, J.; Ferrier, M.L.; Moreau, E.; Freund, N.; Gilbert, T.; Merlet-Benichou, C. Mild vitamin A deficiency leads to inborn nephron deficit in the rat. Kidney Int. 1998, 54, 1455-1462. [CrossRef] [PubMed]

6. Langley-Evans, S.C.; Welham, S.J.; Jackson, A.A. Fetal exposure to a maternal low protein diet impairs nephrogenesis and promotes hypertension in the rat. Life Sci. 1999, 64, 965-974. [CrossRef]

7. Singh, R.R.; Moritz, K.M.; Bertram, J.F.; Cullen-McEwen, L.A. Effects of dexamethasone exposure on rat metanephric development: In vitro and in vivo studies. Am. J. Physiol. Renal. Physiol. 2007, 293, F548-F554. [CrossRef]

8. Cain, J.E.; Di Giovanni, V.; Smeeton, J.; Rosenblum, N.D. Genetics of renal hypoplasia: Insights into the mechanisms controlling nephron endowment. Pediatr. Res. 2010, 68, 91-98. [CrossRef]

9. Lewis, R.M.; Forhead, A.J.; Petry, C.J.; Ozanne, S.E.; Hales, C.N. Long-term programming of blood pressure by maternal dietary iron restriction in the rat. Br. J. Nutr. 2002, 88, 283-290. [CrossRef]

10. Hokke, S.N.; Armitage, J.A.; Puelles, V.G.; Short, K.M.; Jones, L.; Smyth, I.M.; Bertram, J.F.; Cullen-McEwen, L.A. Altered ureteric branching morphogenesis and nephron endowment in offspring of diabetic and insulin-treated pregnancy. PLoS ONE 2013, 8, e58243.

11. Hughson, M.; Farris, A.B., 3rd; Douglas-Denton, R.; Hoy, W.E.; Bertram, J.F. Glomerular number and size in autopsy kidneys: The relationship to birth weight. Kidney Int. 2003, 63, 2113-2122. [CrossRef] [PubMed]

12. Bianchi, G.; Fox, U.; Di Francesco, G.F.; Giovanetti, A.M.; Pagetti, D. Blood pressure changes produced by kidney crosstransplantation between spontaneously hypertensive rats and normotensive rats. Clin. Sci. Mol. Med. 1974, 47, 435-448. [CrossRef] [PubMed]

13. Trowell, O.A. A modified technique for organ culture in vitro. Exp. Cell Res. 1954, 6, 246-248. [CrossRef]

14. Saxen, L.; Lehtonen, E. Embryonic kidney in organ culture. Differentiation 1987, 36, 2-11. [CrossRef]

15. Andersen, A.M.; Vastrup, P.; Wohlfahrt, J.; Andersen, P.K.; Olsen, J.; Melbye, M. Fever in pregnancy and risk of fetal death: A cohort study. Lancet 2002, 360, 1552-1556. [CrossRef]

16. Edwards, M.J. Hyperthermia as a teratogen: A review of experimental studies and their clinical significance. Teratog. Carcinog. Mutagen. 1986, 6, 563-582. [CrossRef] [PubMed]

17. Dreier, J.W.; Andersen, A.M.; Berg-Beckhoff, G. Systematic review and meta-analyses: Fever in pregnancy and health impacts in the offspring. Pediatrics 2014, 133, e674-e688. [CrossRef]

18. Waller, D.K.; Hashmi, S.S.; Hoyt, A.T.; Duong, H.T.; Tinker, S.C.; Gallaway, M.S.; Olney, R.S.; Finnell, R.H.; Hecht, J.T.; Canfield, M.A.; et al. Maternal report of fever from cold or flu during early pregnancy and the risk for noncardiac birth defects, National Birth Defects Prevention Study, 1997-2011. Birth Defects Res. 2018, 110, 342-351. [CrossRef]

19. Abe, K.; Honein, M.A.; Moore, C.A. Maternal febrile illnesses, medication use, and the risk of congenital renal anomalies. Birth Defects Res. A Clin. Mol. Teratol. 2003, 67, 911-918. [CrossRef]

20. Edwards, M.J.; Saunders, R.D.; Shiota, K. Effects of heat on embryos and foetuses. Int. J. Hyperthermia 2003, 19, 295-324. [CrossRef]

21. Edwards, M.J. Congenital defects in guinea pigs: Fetal resorptions, abortions, and malformations following induced hyperthermia during early gestation. Teratology 1969, 2, 313-328. [CrossRef]

22. Black, R.E.; Victora, C.G.; Walker, S.P.; Bhutta, Z.A.; Christian, P.; de Onis, M.; Ezzati, M.; Grantham-McGregor, S.; Katz, J.; Martorell, R.; et al. Maternal and child undernutrition and overweight in low-income and middle-income countries. Lancet 2013, 382, 427-451. [CrossRef] 
23. Lisle, S.J.; Lewis, R.M.; Petry, C.J.; Ozanne, S.E.; Hales, C.N.; Forhead, A.J. Effect of maternal iron restriction during pregnancy on renal morphology in the adult rat offspring. Br. J. Nutr. 2003, 90, 33-39. [CrossRef] [PubMed]

24. Sun, M.Y.; Woolley, J.C.; Blohowiak, S.E.; Smith, Z.R.; Siddappa, A.M.; Magness, R.R.; Kling, P.J. Dietary-induced gestational iron deficiency inhibits postnatal tissue iron delivery and postpones the cessation of active nephrogenesis in rats. Reprod. Fertil. Dev. 2016, 29, 855-866. [CrossRef] [PubMed]

25. Guariguata, L.; Linnenkamp, U.; Beagley, J.; Whiting, D.R.; Cho, N.H. Global estimates of the prevalence of hyperglycaemia in pregnancy. Diabetes Res. Clin. Pract. 2014, 103, 176-185. [CrossRef] [PubMed]

26. Tran, S.; Chen, Y.W.; Chenier, I.; Chan, J.S.; Quaggin, S.; Hebert, M.J.; Ingelfinger, J.R.; Zhang, S.L. Maternal diabetes modulates renal morphogenesis in offspring. J. Am. Soc. Nephrol. 2008, 19, 943-952. [CrossRef] [PubMed]

27. Amri, K.; Freund, N.; Vilar, J.; Merlet-Benichou, C.; Lelievre-Pegorier, M. Adverse effects of hyperglycemia on kidney development in rats: In vivo and in vitro studies. Diabetes 1999, 48, 2240-2245. [CrossRef]

28. Kanwar, Y.S.; Liu, Z.Z.; Kumar, A.; Usman, M.I.; Wada, J.; Wallner, E.I. D-glucose-induced dysmorphogenesis of embryonic kidney. J. Clin. Investig. 1996, 98, 2478-2488. [CrossRef]

29. Kanwar, Y.S.; Akagi, S.; Nayak, B.; Sun, L.; Wada, J.; Xie, P.; Thakur, A.; Chugh, S.S.; Danesh, F.R. Renal-specific oxidoreductase biphasic expression under high glucose ambience during fetal versus neonatal development. Kidney Int. 2005, 68, 1670-1683. [CrossRef]

30. Wanner, N.; Vornweg, J.; Combes, A.; Wilson, S.; Plappert, J.; Rafflenbeul, G.; Puelles, V.G.; Rahman, R.U.; Liwinski, T.; Lindner, S.; et al. DNA Methyltransferase 1 Controls Nephron Progenitor Cell Renewal and Differentiation. J. Am. Soc. Nephrol. 2019, 30, 63-78. [CrossRef]

31. Osterby, R.; Gundersen, H.J. Glomerular size and structure in diabetes mellitus. I. Early abnormalities. Diabetologia 1975, 11, 225-229. [CrossRef] [PubMed]

32. Mac-Moune Lai, F.; Szeto, C.C.; Choi, P.C.; Ho, K.K.; Tang, N.L.; Chow, K.M.; Li, P.K.; To, K.F. Isolate diffuse thickening of glomerular capillary basement membrane: A renal lesion in prediabetes? Mod. Pathol. 2004, 17, 1506-1512. [CrossRef] [PubMed]

33. Al Shawaf, E.; Abu-Farha, M.; Devarajan, S.; Alsairafi, Z.; Al-Khairi, I.; Cherian, P.; Ali, H.; Mathur, A.; Al-Mulla, F.; Al Attar, A.; et al. ANGPTL4: A Predictive Marker for Diabetic Nephropathy. J. Diabetes Res. 2019, 2019, 4943191. [CrossRef] [PubMed]

34. Murakoshi, M.; Tanimoto, M.; Gohda, T.; Hagiwara, S.; Takagi, M.; Horikoshi, S.; Tomino, Y. Mindin: A novel marker for podocyte injury in diabetic nephropathy. Nephrol. Dial. Transpl. 2011, 26, 2153-2160. [CrossRef] [PubMed]

35. Donegan, D.; Bale, L.K.; Conover, C.A. PAPP-A in normal human mesangial cells: Effect of inflammation and factors related to diabetic nephropathy. J. Endocrinol. 2016, 231, 71-80. [CrossRef]

36. Huang, C.; Zhang, Y.; Kelly, D.J.; Tan, C.Y.; Gill, A.; Cheng, D.; Braet, F.; Park, J.S.; Sue, C.M.; Pollock, C.A.; et al. Thioredoxin interacting protein (TXNIP) regulates tubular autophagy and mitophagy in diabetic nephropathy through the mTOR signaling pathway. Sci. Rep. 2016, 6, 29196. [CrossRef] [PubMed]

37. Randhawa, P.K.; Rylova, S.; Heinz, J.Y.; Kiser, S.; Fried, J.H.; Dunworth, W.P.; Anderson, A.L.; Barber, A.T.; Chappell, J.C.; Roberts, D.M.; et al. The Ras activator RasGRP3 mediates diabetes-induced embryonic defects and affects endothelial cell migration. Circ. Res. 2011, 108, 1199-1208. [CrossRef]

38. Zhang, Y.; Han, D.; Yu, P.; Huang, Q.; Ge, P. Genome-scale transcriptional analysis reveals key genes associated with the development of type II diabetes in mice. Exp. Ther. Med. 2017, 13, 1044-1150. [CrossRef]

39. Zheng, X.; Soroush, F.; Long, J.; Hall, E.T.; Adishesha, P.K.; Bhattacharya, S.; Kiani, M.F.; Bhalla, V. Murine glomerular transcriptome links endothelial cell-specific molecule-1 deficiency with susceptibility to diabetic nephropathy. PLoS ONE 2017, 12, e0185250. [CrossRef]

40. Doan, T.N.A.; Briffa, J.F.; Phillips, A.L.; Leemaqz, S.Y.; Burton, R.A.; Romano, T.; Wlodek, M.E.; Bianco-Miotto, T. Epigenetic mechanisms involved in intrauterine growth restriction and aberrant kidney development and function. J. Dev. Orig. Health Dis. 2020, 1-11. [CrossRef]

41. Huang, B.; Liu, Z.; Vonk, A.; Zeng, Z.; Li, Z. Epigenetic regulation of kidney progenitor cells. Stem Cells Transl. Med. 2020, 9, 655-660. [CrossRef] [PubMed]

42. El-Dahr, S.S.; Saifudeen, Z. Epigenetic regulation of renal development. Semin. Cell Dev. Biol. 2019, 91, 111-118. [CrossRef]

43. Liu, H.; Hilliard, S.; Kelly, E.; Chen, C.H.; Saifudeen, Z.; El-Dahr, S.S. The polycomb proteins EZH1 and EZH2 co-regulate chromatin accessibility and nephron progenitor cell lifespan in mice. J. Biol. Chem. 2020, 295, 11542-11558. [CrossRef]

44. Liu, H.; Chen, S.; Yao, X.; Li, Y.; Chen, C.H.; Liu, J.; Saifudeen, Z.; El-Dahr, S.S. Histone deacetylases 1 and 2 regulate the transcriptional programs of nephron progenitors and renal vesicles. Development 2018, 145. [CrossRef] [PubMed]

45. Zhang, L.; Ettou, S.; Khalid, M.; Taglienti, M.; Jain, D.; Jung, Y.L.; Seager, C.; Liu, Y.; Ng, K.H.; Park, P.J.; et al. EED, a member of the polycomb group, is required for nephron differentiation and the maintenance of nephron progenitor cells. Development 2018, 145. [CrossRef] [PubMed]

46. Rumpf, T.; Schiedel, M.; Karaman, B.; Roessler, C.; North, B.J.; Lehotzky, A.; Olah, J.; Ladwein, K.I.; Schmidtkunz, K.; Gajer, M.; et al. Selective Sirt2 inhibition by ligand-induced rearrangement of the active site. Nat. Commun. 2015, 6, 6263. [CrossRef]

47. Senger, J.; Melesina, J.; Marek, M.; Romier, C.; Oehme, I.; Witt, O.; Sippl, W.; Jung, M. Synthesis and Biological Investigation of Oxazole Hydroxamates as Highly Selective Histone Deacetylase 6 (HDAC6) Inhibitors. J. Med. Chem. 2016, 59, 1545-1555. [CrossRef] [PubMed] 
48. Takemoto, Y.; Ito, A.; Niwa, H.; Okamura, M.; Fujiwara, T.; Hirano, T.; Handa, N.; Umehara, T.; Sonoda, T.; Ogawa, K.; et al. Identification of Cyproheptadine as an Inhibitor of SET Domain Containing Lysine Methyltransferase 7/9 (Set7/9) That Regulates Estrogen-Dependent Transcription. J. Med. Chem. 2016, 59, 3650-3660. [CrossRef] [PubMed]

49. Barsyte-Lovejoy, D.; Li, F.; Oudhoff, M.J.; Tatlock, J.H.; Dong, A.; Zeng, H.; Wu, H.; Freeman, S.A.; Schapira, M.; Senisterra, G.A.; et al. (R)-PFI-2 is a potent and selective inhibitor of SETD7 methyltransferase activity in cells. Proc. Natl. Acad. Sci. USA 2014, 111, 12853-12858. [CrossRef]

50. Roatsch, M.; Hoffmann, I.; Abboud, M.I.; Hancock, R.L.; Tarhonskaya, H.; Hsu, K.F.; Wilkins, S.E.; Yeh, T.L.; Lippl, K.; Serrer, K.; et al. The Clinically Used Iron Chelator Deferasirox Is an Inhibitor of Epigenetic JumonjiC Domain-Containing Histone Demethylases. ACS Chem. Biol. 2019, 14, 1737-1750. [CrossRef]

51. Luo, X.; Liu, Y.; Kubicek, S.; Myllyharju, J.; Tumber, A.; Ng, S.; Che, K.H.; Podoll, J.; Heightman, T.D.; Oppermann, U.; et al. A selective inhibitor and probe of the cellular functions of Jumonji C domain-containing histone demethylases. J. Am. Chem. Soc. 2011, 133, 9451-9456. [CrossRef] [PubMed]

52. Gajer, J.M.; Furdas, S.D.; Grunder, A.; Gothwal, M.; Heinicke, U.; Keller, K.; Colland, F.; Fulda, S.; Pahl, H.L.; Fichtner, I.; et al. Histone acetyltransferase inhibitors block neuroblastoma cell growth in vivo. Oncogenesis 2015, 4, e137. [CrossRef]

53. Carneiro, V.C.; de Abreu da Silva, I.C.; Torres, E.J.; Caby, S.; Lancelot, J.; Vanderstraete, M.; Furdas, S.D.; Jung, M.; Pierce, R.J.; Fantappie, M.R. Epigenetic changes modulate schistosome egg formation and are a novel target for reducing transmission of schistosomiasis. PLoS Pathog. 2014, 10, e1004116. [CrossRef] [PubMed]

54. Willmann, D.; Lim, S.; Wetzel, S.; Metzger, E.; Jandausch, A.; Wilk, W.; Jung, M.; Forne, I.; Imhof, A.; Janzer, A.; et al. Impairment of prostate cancer cell growth by a selective and reversible lysine-specific demethylase 1 inhibitor. Int. J. Cancer 2012, 131, 2704-2709. [CrossRef]

55. Schmitt, M.L.; Hauser, A.T.; Carlino, L.; Pippel, M.; Schulz-Fincke, J.; Metzger, E.; Willmann, D.; Yiu, T.; Barton, M.; Schule, R.; et al. Nonpeptidic propargylamines as inhibitors of lysine specific demethylase 1 (LSD1) with cellular activity. J. Med. Chem. 2013, 56, 7334-7342. [CrossRef] [PubMed]

56. Heimburg, T.; Chakrabarti, A.; Lancelot, J.; Marek, M.; Melesina, J.; Hauser, A.T.; Shaik, T.B.; Duclaud, S.; Robaa, D.; Erdmann, F.; et al. Structure-Based Design and Synthesis of Novel Inhibitors Targeting HDAC8 from Schistosoma mansoni for the Treatment of Schistosomiasis. J. Med. Chem. 2016, 59, 2423-2435. [CrossRef]

57. Tatamiya, T.; Saito, A.; Sugawara, T.; Nakanishi, O. Isozyme-Selective Activity of the HDAC inhibitor MS-275; AACR: Phila-delphia, PA, USA, 2004.

58. Sharma, N.; Sankrityayan, H.; Kale, A.; Gaikwad, A.B. Role of SET7/9 in the progression of ischemic renal injury in diabetic and non-diabetic rats. Biochem. Biophys. Res. Commun. 2020, 528, 14-20. [CrossRef] [PubMed]

59. Hirano, T.; Fujiwara, T.; Niwa, H.; Hirano, M.; Ohira, K.; Okazaki, Y.; Sato, S.; Umehara, T.; Maemoto, Y.; Ito, A.; et al. Development of Novel Inhibitors for Histone Methyltransferase SET7/9 based on Cyproheptadine. ChemMedChem 2018, 13, 1530-1540. [CrossRef]

60. Keijzer-Veen, M.G.; Schrevel, M.; Finken, M.J.; Dekker, F.W.; Nauta, J.; Hille, E.T.; Frolich, M.; van der Heijden, B.J.; Dutch, P.-C.S.G. Microalbuminuria and lower glomerular filtration rate at young adult age in subjects born very premature and after intrauterine growth retardation. J. Am. Soc. Nephrol. 2005, 16, 2762-2768. [CrossRef]

61. Hurtado Del Pozo, C.; Garreta, E.; Izpisua Belmonte, J.C.; Montserrat, N. Modeling epigenetic modifications in renal development and disease with organoids and genome editing. Dis. Model Mech. 2018, 11. [CrossRef]

62. Nurtjahja-Tjendraputra, E.; Fu, D.; Phang, J.M.; Richardson, D.R. Iron chelation regulates cyclin D1 expression via the proteasome: A link to iron deficiency-mediated growth suppression. Blood 2007, 109, 4045-4054. [CrossRef] [PubMed]

63. Swali, A.; McMullen, S.; Hayes, H.; Gambling, L.; McArdle, H.J.; Langley-Evans, S.C. Processes underlying the nutritional programming of embryonic development by iron deficiency in the rat. PLoS ONE 2012, 7, e48133. [CrossRef] [PubMed]

64. Mandala, A.; Armstrong, A.; Girresch, B.; Zhu, J.; Chilakala, A.; Chavalmane, S.; Chaudhary, K.; Biswas, P.; Ogilvie, J.; GnanaPrakasam, J.P. Fenofibrate prevents iron induced activation of canonical Wnt/beta-catenin and oxidative stress signaling in the retina. NPJ Aging Mech. Dis. 2020, 6, 12. [CrossRef] [PubMed]

65. Song, S.; Christova, T.; Perusini, S.; Alizadeh, S.; Bao, R.Y.; Miller, B.W.; Hurren, R.; Jitkova, Y.; Gronda, M.; Isaac, M.; et al. Wnt inhibitor screen reveals iron dependence of beta-catenin signaling in cancers. Cancer Res. 2011, 71, 7628-7639. [CrossRef]

66. Zhao, X.-P.; Liao, M.-C.; Chang, S.-Y.; Abdo, S.; Aliou, Y.; Chenier, I.; Ingelfinger, J.R.; Zhang, S.-L. Maternal diabetes modulates kidney formation in murine progeny: The role of hedgehog interacting protein (HHIP). Diabetologia 2014, 57, 1986-1996. [CrossRef] [PubMed]

67. Chang, S.-Y.; Chen, Y.-W.; Zhao, X.-P.; Chenier, I.; Tran, S.; Sauvé, A.; Ingelfinger, J.R.; Zhang, S.-L. Catalase prevents maternal diabetes-induced perinatal programming via the Nrf2-HO-1 defense system. Diabetes 2012, 61, 2565-2574. [CrossRef] [PubMed]

68. Chen, Y.-W.; Chenier, I.; Tran, S.; Scotcher, M.; Chang, S.-Y.; Zhang, S.-L. Maternal diabetes programs hypertension and kidney injury in offspring. Pediatric Nephrol. 2010, 25, 1319-1329. [CrossRef]

69. Chen, Y.-W.; Chenier, I.; Chang, S.-Y.; Tran, S.; Ingelfinger, J.R.; Zhang, S.-L. High glucose promotes nascent nephron apoptosis via NF-kB and p53 pathways. Am. J. Physiol. Ren. Physiol. 2010, 300, F147-F156. [CrossRef]

70. Nehiri, T.; Van Huyen, J.-P.D.; Viltard, M.; Fassot, C.; Heudes, D.; Freund, N.; Deschênes, G.; Houillier, P.; Bruneval, P.; LelièvrePégorier, M. Exposure to maternal diabetes induces salt-sensitive hypertension and impairs renal function in adult rat offspring. Diabetes 2008, 57, 2167-2175. [CrossRef] 
71. França-Silva, N.; Oliveira, N.D.G.; Balbi, A.P.C. Morphofunctional renal alterations in rats induced by intrauterine hyperglycemic environment. Arch. Med. Sci. AMS 2016, 12, 243. [CrossRef]

72. Pani, L.; Horal, M.; Loeken, M.R. Polymorphic susceptibility to the molecular causes of neural tube defects during diabetic embryopathy. Diabetes 2002, 51, 2871-2874. [CrossRef] [PubMed]

73. Buchanan, T.A.; Denno, K.M.; Sipos, G.F.; Sadler, T.W. Diabetic teratogenesis. In vitro evidence for a multifactorial etiology with little contribution from glucose per se. Diabetes 1994, 43, 656-660. [CrossRef] [PubMed]

74. Wentzel, P.; Eriksson, U.J. Insulin treatment fails to abolish the teratogenic potential of serum from diabetic rats. Eur. J. Endocrinol. 1996, 134, 459-466. [CrossRef]

75. El Hajj, N.; Pliushch, G.; Schneider, E.; Dittrich, M.; Muller, T.; Korenkov, M.; Aretz, M.; Zechner, U.; Lehnen, H.; Haaf, T. Metabolic programming of MEST DNA methylation by intrauterine exposure to gestational diabetes mellitus. Diabetes 2013, 62, 1320-1328. [CrossRef] [PubMed]

76. Anguita-Ruiz, A.; Mendez-Gutierrez, A.; Ruperez, A.I.; Leis, R.; Bueno, G.; Gil-Campos, M.; Tofe, I.; Gomez-Llorente, C.; Moreno, L.A.; Gil, A.; et al. The protein S100A4 as a novel marker of insulin resistance in prepubertal and pubertal children with obesity. Metabolism 2020, 105, 154187. [CrossRef] [PubMed]

77. Hjort, L.; Martino, D.; Grunnet, L.G.; Naeem, H.; Maksimovic, J.; Olsson, A.H.; Zhang, C.; Ling, C.; Olsen, S.F.; Saffery, R.; et al. Gestational diabetes and maternal obesity are associated with epigenome-wide methylation changes in children. JCI Insight 2018, 3. [CrossRef] [PubMed]

78. Quilter, C.R.; Cooper, W.N.; Cliffe, K.M.; Skinner, B.M.; Prentice, P.M.; Nelson, L.; Bauer, J.; Ong, K.K.; Constancia, M.; Lowe, W.L.; et al. Impact on offspring methylation patterns of maternal gestational diabetes mellitus and intrauterine growth restraint suggest common genes and pathways linked to subsequent type 2 diabetes risk. FASEB J. 2014, 28, 4868-4879. [CrossRef] [PubMed]

79. Hilliard, S.A.; El-Dahr, S.S. Epigenetics mechanisms in renal development. Pediatric Nephrol. 2016, 31, 1055-1060. [CrossRef]

80. Wanner, N.; Bechtel-Walz, W. Epigenetics of kidney disease. Cell Tissue Res. 2017, 369, 75-92. [CrossRef]

81. Bechtel, W.; McGoohan, S.; Zeisberg, E.M.; Muller, G.A.; Kalbacher, H.; Salant, D.J.; Muller, C.A.; Kalluri, R.; Zeisberg, M. Methylation determines fibroblast activation and fibrogenesis in the kidney. Nat. Med. 2010, 16, 544-550. [CrossRef]

82. Chen, S.; Yao, X.; Li, Y.; Saifudeen, Z.; Bachvarov, D.; El-Dahr, S.S. Histone deacetylase 1 and 2 regulate Wnt and p53 pathways in the ureteric bud epithelium. Development 2015, 142, 1180-1192. [CrossRef]

83. Rosenberg, S.L.; Chen, S.; McLaughlin, N.; El-Dahr, S.S. Regulation of kidney development by histone deacetylases. Pediatric Nephrol. 2011, 26, 1445-1452. [CrossRef] [PubMed]

84. Kobayashi, A.; Valerius, M.T.; Mugford, J.W.; Carroll, T.J.; Self, M.; Oliver, G.; McMahon, A.P. Six2 defines and regulates a multipotent self-renewing nephron progenitor population throughout mammalian kidney development. Cell Stem Cell 2008, 3, 169-181. [CrossRef]

85. Kumaki, Y.; Oda, M.; Okano, M. QUMA: Quantification tool for methylation analysis. Nucleic Acids Res. 2008, 36, W170-W175. [CrossRef] [PubMed]

86. Trapnell, C.; Pachter, L.; Salzberg, S.L. TopHat: Discovering splice junctions with RNA-Seq. Bioinformatics 2009, $25,1105-1111$. [CrossRef]

87. Anders, S.; Pyl, P.T.; Huber, W. HTSeq-a Python framework to work with high-throughput sequencing data. Bioinformatics 2015, 31, 166-169. [CrossRef] [PubMed]

88. Love, M.I.; Huber, W.; Anders, S. Moderated estimation of fold change and dispersion for RNA-seq data with DESeq2. Genome Biol. 2014, 15, 550. [CrossRef]

89. Cohen, C.D.; Frach, K.; Schlondorff, D.; Kretzler, M. Quantitative gene expression analysis in renal biopsies: A novel protocol for a high-throughput multicenter application. Kidney Int. 2002, 61, 133-140. [CrossRef] [PubMed]

90. Cohen, C.D.; Klingenhoff, A.; Boucherot, A.; Nitsche, A.; Henger, A.; Brunner, B.; Schmid, H.; Merkle, M.; Saleem, M.A.; Koller, K.P.; et al. Comparative promoter analysis allows de novo identification of specialized cell junction-associated proteins. Proc. Natl. Acad. Sci. USA 2006, 103, 5682-5687. [CrossRef]

91. Tusher, V.G.; Tibshirani, R.; Chu, G. Significance analysis of microarrays applied to the ionizing radiation response. Proc. Natl. Acad. Sci. USA 2001, 98, 5116-5121. [CrossRef]

92. Mamo, S.; Gal, A.B.; Bodo, S.; Dinnyes, A. Quantitative evaluation and selection of reference genes in mouse oocytes and embryos cultured in vivo and in vitro. BMC Dev Biol. 2007, 7, 14. [CrossRef] [PubMed] 